University of New Hampshire

University of New Hampshire Scholars' Repository

Center for Coastal and Ocean Mapping

Center for Coastal and Ocean Mapping

$6-2010$

\title{
Simulating an Airborne Lidar Bathymetry (ALB) System
}

\author{
Shachak Pe'eri \\ University of New Hampshire, Durham, shachak.peeri@unh.edu \\ Amaresh M. Kumar \\ University of New Hampshire, Durham \\ Brian R. Calder \\ University of New Hampshire, Durham, brian.calder@unh.edu
}

Follow this and additional works at: https://scholars.unh.edu/ccom

Part of the Computer Sciences Commons, and the Oceanography and Atmospheric Sciences and Meteorology Commons

\section{Recommended Citation}

Pe'eri, Shachak; Kumar, Amaresh M.; and Calder, Brian R., "Simulating an Airborne Lidar Bathymetry (ALB) System" (2010). Optical Remote Sensing of the Environment (ORS). 516.

https://scholars.unh.edu/ccom/516

This Conference Proceeding is brought to you for free and open access by the Center for Coastal and Ocean Mapping at University of New Hampshire Scholars' Repository. It has been accepted for inclusion in Center for Coastal and Ocean Mapping by an authorized administrator of University of New Hampshire Scholars' Repository. For more information, please contact Scholarly.Communication@unh.edu. 


\title{
Simulating an Airborne Lidar Bathymetry (ALB) System
}

\author{
Shachak Pe’eri, Amaresh M. V. Kumar, and Brian R. Calder \\ Center for Coastal and Ocean Mapping, University of New Hampshire, Durham, NH 03824, USA
}

\begin{abstract}
This study's focus is on the horizontal and vertical uncertainties associated with ALB measurements due to scattering through the water column. A lidar simulator was constructed and we present its design and preliminary results.

OCIS codes: (280.3640) Lidar; (010.4458); Oceanic scattering (120.3620); Optical standards and testing; (120.5820) Scattering measurements
\end{abstract}

\section{Summary}

Airborne lidar bathymetry (ALB) has become a conventional method to measure both the topography and bathymetry of nearshore coastal waters and lakes from a low-altitude aircraft using a scanning, pulsed laser beam. The ALB systems uses a Nd:YAG laser that emits pulses at two wavelengths; (1) at $1064 \mathrm{~nm}$ in the Infrared (IR), the fundamental wavelength of the Nd:YAG laser, and (2) in the green at $532 \mathrm{~nm}$, produced by frequency doubling of the fundamental wavelength. These wavelengths are particularly useful given the optical properties of water. According to light attenuation measurements by [1], laser pulses transmitted at the $532 \mathrm{~nm}$ wavelength are near the spectral absorption minimum for most waters and that wavelength is considered nearly ideal for water penetration in typical coastal waters. Accordingly, the green $(532 \mathrm{~nm})$ is the primary wavelength used in ALB surveying. As we try to understand the value of ALB-derived data for a number of hydrographic applications, it is increasingly apparent that there are many uncertainties associated with the system that are not well understood. Most critical among these are the questions of what happens to an ALB laser beam once it strikes the sea and enters the water column. To address these issues, a lidar simulator was constructed and here we present its design and preliminary results.

The ray-path geometry of the transmitted green-laser pulse begins with a first interaction with the water surface. Only a small portion of the total energy is returned toward the detector and the remaining portion is refracted into the water column. Once the laser beam has entered the water column, each individual photon may be elastically or inelastically scattered or absorbed. Suspended particulates in the water column cause the laser pulse-energy to be scattered at the same wavelength that the laser pulse was transmitted (elastic scattering) and is usually modeled as Mie scattering [2]. As the transmitted energy of the laser pulse passes down the water column, a fraction of the energy is scattered back up through the water column. The magnitude of the laser-pulse energy exponentially decreases according to the apparent optical properties of the water column (the diffuse attenuation coefficient, K). The final downward interaction of the green laser pulse is with the bottom, where a portion of the energy incident on the seafloor (typically $4 \%$ to $15 \%$, depending on the angle of incidence, rugosity, and bottom composition) is diffusely reflected from the bottom back into the water and collected by the ALB system [3].

Most studies on the uncertainty associated with measurements from an ALB are empirical measurements based on either topographic measurements (topographic lidar, terrestrial laser scanner, or GPS) or bathymetric (singlebeam or multibeam echosounders). The results from the comparison do not take into account the different hardware and environmental factors that affect the laser measurement, and focus only on the final product. In order to understand the different properties contributing to the uncertainty, numerous test sites containing different environmental scenarios need to be examined. This approach is very costly and hard to achieve. This study presents results on the optic configuration of a lidar simulator system with full-waveform recording capabilities. The two main goals for construction of this system are: (1) to measure the ray-path geometry of a laser pulse through the water column; and (2) to conduct a beam diagnostics of the laser pulse at different water depths.

The lidar simulator is a co-axial system (a system using a single optic axis for transmitting and receiving the light beam) which includes a source, a transeiver (a combined transmitter and receiver), and a detector unit. The lidar simulator allows the operator to conduct experiments for different lidar configurations (e.g., scan angles and beam divergence) in a well-controlled environment. The source is a pulsed Nd:YAG laser transmitting pulses with a time duration of $5 \mathrm{~ns}$ and a variable pulse energy of maximum up to $23 \mathrm{~mJ}$. The trans-receiver system is a Dobsonian telescope system. The telescope operates as a transmitter by expanding a $3 \mathrm{~mm}$ laser-beam diameter from the laser to a diameter of $20 \mathrm{~cm}$ onto the water surface while maintaining a small beam divergence $(\sim 10 \mathrm{mrad})$. The telescope then operates as a receiver collecting the energy reflected back from the pulse's interaction with the water 


\section{OMC4.pdf}

body. The detector unit includes optical filters, an avalanche photodiode (APD) module, and a digitizer. The digitizer is a $500 \mathrm{MHz}$ bandwidth oscilloscope that samples the received energy as a function of time (2 ns bins) and presents it as a waveform. In addition, a power meter was added to the lidar simulator system. This allows monitoring the transmitted and received energy and providing physical values to the collected waveform. The lidar simulator is operational and has been mounted over a small water tank (water depth $\sim 0.6 \mathrm{~m}$ ). At the moment, only calibration measurements have been conducted, however preliminary results show the influence of the diffuse attenuation coefficient on the recorded waveforms. Theoretical calculations and optic design simulations have also been conducted using ZEMAX.

The lidar simulator will aid in predicting the location of the laser measurements on the seafloor and predicting horizontal and vertical displacements due to water clarity. As a result, a better estimate of the lidar propagation uncertainty can be produced. The results of this study will also improve the understanding of the uncertainty related to optical behavior of ALB waveforms under different environmental conditions. To the knowledge of the authors, the only remotely measured littoral parameter for which uncertainty is estimated is acoustically-resolved bathymetry [4]. A physical understanding of the interaction between a given sensor measurement and the environment will focus only on the remote sensing method and will remove the dependence on a specific sensor model.

\section{References}

[1] N. G. Jerlov, N.G., 1976. “Marine Optics,” (Elsevier Scientific Publication, 1976).

[2] R. M. Measures, “Laser Remote Sensing: Fundamentals and Applications,” (Kreiger Publishing Company, 1992).

[3] G. C. Guenther, “Airborne Laser Hydrography: System design and performance factors,” (NOS, NOAA, Rockville, MD, NOAA Prof. Paper Ser., March, 1985).

[4] B. Calder, “On the Uncertainty of Archive Hydrographic Data Sets,” IEEE JOE 31, 249-265, 2006 